Article

\title{
The Power of Urban Planning on Environmental Sustainability: A Focus Group Study in Finland ${ }^{\dagger}$
}

\section{Eeva-Sofia Säynäjoki $^{1, *}$, Jukka Heinonen ${ }^{1,2}$ and Seppo Junnila ${ }^{1}$}

1 Department of Real Estate, Planning and Geoinformatics, Aalto University School of Engineering, P.O. Box 15800, FI-00076 AALTO, Espoo 02150, Finland; E-Mail: seppo.junnila@aalto.fi

2 Faculty of Civil and Environmental Engineering, University of Iceland, VR-II, Hjarðarhaga 2-6, 107 Reykjavík, Iceland; E-Mail: heinonen@hi.is

$\dagger$ The research material has been utilised in a preliminary study, and some preliminary results have been presented at CIB International Conference on "Construction in a Changing World", Dambulla, Sri Lanka, 4-7 May 2014.

* Author to whom correspondence should be addressed; E-Mail: eeva.saynajoki@aalto.fi; Tel.: +358-504-086-126.

External Editor: Marc A. Rosen

Received: 26 June 2014; in revised form: 22 August 2014 / Accepted: 17 September 2014 / Published: 29 September 2014

\begin{abstract}
Sustainable communities are promoted as a desirable policy goal and, in particular, local authorities are encouraged to contribute to climate change mitigation through urban planning. Furthermore, recent research takes a broad perspective on the environmental sustainability of urban areas and considers the environmental impact of all consumption. A focus group study was conducted in Finland for the purpose of examining how increased environmental awareness influences urban land use. The 32 participants of three focus groups were professionals of urban planning and environmental sustainability, at both a municipal and a state level. The main finding was that urban planning is viewed as being unable to support environmental sustainability in the broader sense. In general, the participants did not see a connection between urban structure and sustainable lifestyles and only the influence of planning on housing and daily journeys was recognised. Three main reasons for this were identified. Firstly, environmental sustainability in its broader definition is seen as too complex for urban planners to influence alone. Secondly, the dominance of short-term economic issues in decision-making and the lack of co-operation
\end{abstract}


from other stakeholders to achieve environmental aims demotivate land use planners. Thirdly, the prioritisation of urban density may overrule alternative means of promoting environmental sustainability, such as the encouragement of sustainable suburban or non-urban lifestyles.

Keywords: environmental sustainability; urban planning; municipalities; focus groups; strategic environmental assessment; decision-making; urban density; sustainable lifestyles

\section{Introduction}

The very purpose of urban planning is to prepare for the future, or more ambitiously, to create better futures [1]. Over the past century, massive urban population growth has occurred on less than 3\% of the global terrestrial surface but the environmental impact has been widespread: $75 \%$ of greenhouse gas emissions can be attributed to cities and the ecological footprint of the cities is tens to hundreds of times larger than the actual urban area occupied [2]. Attention has been drawn to the importance of urban planning as a means through which to address the global environmental challenges given rise to by cities, and transforming urban areas into sustainable communities is becoming an increasingly common vision $[3,4]$.

Sustainability schemes, such as the British BREEAM for Communities, the Japanese CASBEE for Urban Development and the American LEED for Neighborhood Development, are already being used for the certification and benchmarking of urban areas. Sustainable communities are promoted as a desirable policy goal and local authorities are encouraged to contribute to, in particular, climate change mitigation through urban planning [3,5]. Nevertheless, there are competing discourses on environmental sustainability and a lack of certainty about what it might mean in practice $[3,5,6]$. Urban planners often appear to struggle with the issue of how to promote area-specific urban environmental quality through municipal land use planning $[7,8]$.

For the purpose of examining and describing the correlations between urban form and environmental sustainability a wide variety of indicators, such as compactness, centrality, density, porosity, complexity, patch size, land consumption per capita, land-use mix and accessibility, has been developed [9-14]. Recently, Schwarz [12] analysed the urban form of more than two hundred European cities to investigate how many different indicators are actually needed to describe the variety. He applied both landscape metrics and population-related indicators, and concluded that a minimal set for urban form consists of seven indicators that are: the area of the discontinuous urban fabric, edge density, mean patch size, number of patches, compactness index of the largest patch, population number, and population density.

In political discussion, the term urban density is often taken to roughly represent an appropriate combination of the more specific indicators for urban form [15]. An area of high urban density is typically both compact in structure and densely populated. Nevertheless, for land use planners, high urban density tends to be interpreted comparatively and in local use it often refers to the intensive use of available urban space rather than to building urban structures in densities that are considered high on a world scale [16,17]. In the context of urban planning, dwelling density, density of green space, 
road density, traffic density, population density and employment density are commonly used specifications of urban density [15].

Many scholars and practitioners hold the view that the prevention of urban sprawl through combining high population density with the compactness of urban structures has an important role in developing environmentally sustainable societies [17-20]. Short distances facilitate walking, cycling, and public transportation, which can reduce the use of motor vehicles. Smaller apartments require less space heating, and dense housing can use waste process heat from industry and power plants. In addition, density enables cost- and eco-efficient centralised sewer systems, waste collection and material recycling. On the other hand however, high urban density is claimed to deteriorate the environmental and spatial quality of the built environment [20,21]. Furthermore, the environmental advantages of compactness may be over-estimated or even be nullified due to the negative environmental impact of consumption that tends to increase with urban densification [16,22-24]. As such, recent Nordic studies, among others, call for a broader view on the environmental sustainability of urban areas whereby the environmental impact of all consumption would be considered [25-27].

State level governing institutions outline decisions about urban form, urban planners shape them and local authorities (councillors on planning committees) approve the decisions [15,17]. Local autonomy in land use planning is high, and the outcome of the successful implementation of environmental policy at a municipal level should be sustainable urban development [17]. Nevertheless, according to Bulkeley [28], there is a gap between rhetoric and action in environmental governance at a city level. The gap stems from issues of institutional capacity and factors of the political economy [28]. Jordan and Lenschow [29] point to a disconnection between policy and practice when it comes to environmental policy integration. A widespread political commitment to environmental sustainability has been recognised at a general discursive level, but agreement around its positive meaning in day-to-day decision-making is sparse [29].

Given that most studies have focused on the technical challenges of urban sustainability, the related political struggles have not yet been widely researched [30,31]. Furthermore, analyses have often been restricted to the local scale and ignored the multilevel political system through which the environmental governance of local economies is conducted $[32,33]$. The extent to which municipal land use planning can address the challenges of environmental sustainability should thus be examined [3].

The purpose of this focus group study is to examine how professionals in urban planning and environmental sustainability in Finland experience the steering effect of increased environmental awareness on urban land use. The more specific research questions are:

(1) Why is environmental sustainability assessed in urban planning?

(2) How does environmental assessment steer decision-making in urban planning?

(3) What is the role of urban planning and urban planners in environmental sustainability?

(4) How is urban density considered in terms of environmentally sustainable land use?

This paper focuses on urban areas, which can be regarded as the demand and consumption centres of the global economy and thus as the root cause of environmental degradation [34,35]. The term land use planning (as opposed to urban planning) also incorporates the management of non-urban territory, where the effects of environmental degradation, such as land degradation, biodiversity loss and the disturbance of nitrogen and phosphorus cycles, to name but a few, can be observed. This intrinsic link 
between actions in urban areas and environmental consequences in non-urban areas should therefore be recognised.

The paper is structured as follows: Section 2 introduces the research methods and the material used. The results of the analysis are presented in Section 3, and the findings are discussed in Section 4. Finally, Section 5 concludes the paper.

\section{Research Design}

As the focus of the study was not solely on what people think but on how they articulate, rationalise, challenge each other's views and potentially question their own views, it was opted to conduct research based on in-depth group work. For the purpose of data collection, focus groups were organised to bring together an inclusive set of urban planning professionals and to enable informal interactive discussions. Three focus groups were conducted in the city of Helsinki in April 2013.

\subsection{Focus Group Method}

The first use of focus groups in an environmental context was by Burgess and Harrison [36], whose analysis identified a need for organisations to match their practices with their environmental rhetoric. Earlier, in the 1920s, focus groups were being used for market research [37] and in the 1950s to assess the public's response to wartime propaganda [38]. The groups are 'focused' in the sense that all interviewees take part in a collective activity and are distinguished from the broader category of group interviews by 'the explicit use of the group interaction' as research data [39]. Morgan [40] defines focus groups as "a research technique that collects data through group interaction on a topic predetermined by the researcher". The interaction often takes unexpected turns and may provide researchers with surprising insights and unexpected findings [41].

Given that the interaction in focus groups typically forces the participants to explain the reasoning behind their thinking, the method allows the researcher to observe not only how people theorise their own point of view but also how they do so in relation to other perspectives [39]. Focus groups are particularly useful in studies where the researcher seeks to uncover attitudes, perceptions and beliefs [41]. It is critical, however, to recognise certain problems of group dynamics and to be cautious especially when making claims for empowerment and inclusivity [42,43]. The facilitator has to ensure that all participants have an equal chance to contribute, even if often being unable to uncover all the complex interrelationships within the group. When a participant is asked to explain a view, there is a risk that probes are eliciting merely rationalisations as opposed to the real reasons. To overcome this, provocation and open questions can be used carefully to develop the discourse $[43,44]$.

\subsection{Thematic Analysis of Focus Group Data}

While focus groups are widely used as a data collection technique, the method has been criticised for the lack of established guidance for data analysis and interpretation [45]. Given the general intention of focus groups, the analysis differs from more traditional survey methods in that less importance is attributed to the use of counts and statistics and a rich investigation of content takes 
precedence [45]. In addition, the group can serve as the fundamental unit of analysis, such that single responses are seen as being expressed in a larger social context [46,47].

According to Guest et al. [48], thematic analysis is the most useful data analysis technique in capturing the complexities of meaning within a qualitative data set. Put simplistically, thematic analysis moves beyond counting words or phrases and focuses instead on identifying and describing themes. However, previous research has demonstrated that informal and sometimes poorly described forms of thematic analyses are commonplace in many focus group-based studies, whereby the selection of interesting quotes forms the basis of data reduction $[45,49]$.

For the purpose of increasing the specificity and transparency of the data analysis process, Massey [45] suggests that the data derived from the raw material of focus group transcripts falls into three levels, which fit the thematic approach to latent data analysis: articulated, attributional and emergent. Articulated data arises in participants' direct responses to the questions that the researcher poses to guide the discussion. In contrast, some hypotheses or research questions may be more successfully addressed without direct questioning [47,50]. The resulting attributional data extends beyond the questions posed in situ, and is derived instead from the research questions or hypotheses that are brought indirectly into the study, with the expectation that the most critical issues will surface in the conversation. Finally, emergent data contributes to new insights and hypothesis formulation and is the unanticipated product of group interaction [45].

According to Massey [45], the analysis of focus group data should neither confuse nor conflate the information that arises from each of the three levels introduced above. A researcher should make the intentions explicit and identify the kind of data that will be most relevant to the purpose of the study.

\subsection{Data Collection}

The intention of this study was to learn more about the attitudes and opinions of the participants, which is one of the traditional uses of the focus group method [51]. The research objectives necessitated the focus group participants to extensively represent the urban planning professionals in Finland. To ensure an adequate sample and to reduce bias, the focus groups were conducted as part of a workshop that offered the participants additional value; their participation in the study was not the sole grounds for their attendance. The overall theme of the workshop was to introduce and discuss the aims of a research project, launched to develop a new national eco-efficiency evaluation scheme for land-use planning in Finland. The workshop was designed to support the focus group study, and the participants were informed about the research purposes and the applied techniques of data collection.

The group participants consisted of 32 urban planning professionals and related specialists from fourteen Finnish cities, the Finnish environment ministry, two architectural firms, four consulting companies, one of Finland's largest energy companies, a market leading construction company, the Green Building Council Finland and the Finnish Association of Building Owners and Construction Clients (RAKLI). Participants were divided into three separate focus groups, detailed in Table 1, each of which was moderated by a researcher. A limit of 12 participants was placed on group size in order to provide all participants with a chance to contribute. 
Table 1. The organisations represented by the participants of each focus group.

\begin{tabular}{lccccc}
\hline & Focus Group 1 & Focus Group 2 & & Focus Group 3 \\
\hline 1 & The city of Helsinki & 1 & The city of Espoo & 1 & The city of Vantaa \\
2 & The city of Tampere & 2 & The city of Tampere & 2 & The city of Tampere \\
3 & The city of Joensuu & 3 & The city of Lohja & 3 & The city of Lohja \\
4 & The city of Lappeenranta & 4 & The city of Kokkola & 4 & The city of Kotka \\
5 & The city of Pori & 5 & The city of Kouvola & 5 & The city of Lahti \\
6 & Construction company \#1 & 6 & The city of Kuopio & 6 & The city of Mikkeli \\
7 & Energy company \#1 & 7 & The city of Lappeenranta & 7 & Ministry of the Environment \\
8 & Green Building Council Finland & 8 & Green Building Council Finland & 8 & RAKLI \\
9 & Consulting company \#1 & 9 & Architectural firm \#1 & 9 & Architectural firm \#2 \\
10 & Consulting company \#2 & 10 & Consulting company \#3 & 10 & Consulting company \#2 \\
& & 11 & Consulting company \#4 & 11 & Consulting company \#4 \\
\hline
\end{tabular}

Each listing represents an individual participant.

To standardise the leadership of the discourse, the three moderators followed the same specific procedures, which were printed and distributed to the moderators only. The instructions for the probes and prompts were designed on the one hand to reflect the purpose of the study and on the other hand to allow for different group dynamics. In addition, an oral presentation with visual elements was developed to guide the group discussions.

The presentation, given to all participants as a single group, prior to the commencement of the individual group sessions, provided background information on the study and posed a series of direct questions that discussions were to focus on:

(1) Why is environmental sustainability assessed in urban planning?

(2) How does environmental assessment steer decision-making in urban planning?

(3) What is the role of urban planning in environmental sustainability?

Perhaps even more important were the more specific questions that were not directly posed:

(4) How is the power of urban planners to promote environmental sustainability limited?

(5) How is urban density considered in terms of environmentally sustainable land use?

As mentioned above, some research questions may be more successfully addressed by means other than direct questioning. Questions (4) and (5) were considered too leading to be asked directly. Instead, it was hypothesised that these issues would emerge in the conversations, inspired by the direct questions that were purposefully couched in more general terms. The intention here was to allow the participants to approach the subjects voluntarily, perhaps from an unexpected perspective, and to collect attributional data.

As is typical of focus groups, even though they were conducted according to the same guidelines [39-41,43], each conversation had its own dynamic and direction. The moderators' role was to enhance interaction and to ensure that all participants had an equal chance to contribute. Within these limits, much of the discussion was left to the participants in order to learn what they found interesting and important. Nevertheless, occasionally the moderators attempted to develop the discourses by encouraging the participants to explain their views, or even through discreet provocation. The group discussions, each approximately an hour in length, were audio-recorded and manually 
transcribed and also video-recorded. In parallel with the recordings, the moderators made notes concerning mainly the atmosphere, the interaction and the participants' reactions.

\subsection{Data Analysis}

A thematic analysis was conducted on the data that emerged from the focus groups: the video and audio recordings of the three discussions, the transcripts and the notes made by the three moderators. The data was interpreted at two of the three levels Massey [45] suggests: articulated and attributional. No emergent data was identified.

As the first data display, a set of codes was developed to represent the identified themes and was manually applied to the transcripts (raw data) as summary markers for later analysis. Two of the focus group discussions consisted of a similar amount of exchanges between participants: one had 64 individual spoken lines and the other had 68. The third one was far more discursive and 120 spoken lines were noted. Given that interaction was considered to be an important element of the data, rather than dividing the raw data into transcripts of individual lines, the codes were applied to transcripts of a full discursive exchange. Each of the five questions listed above was allocated its own code, and any chunk of text that was even slightly related to one of the questions was marked with the respective code. It was often the case that the same piece of data was demarcated with multiple codes. Any transcribed lines which did not contribute to any of the six questions were set aside. This formed the main method of data reduction.

As the second data display, relevant parts of the data were manually grouped by each theme's code and a secondary, more specific categorisation was conducted within each question's data set. Here, more explicit citations were extracted from the larger, catalogued chunks of text. The citations that required sub-coding were itemised in tables. The citations were generally a sequence of words revealing one or several distinct messages, either from a single contributor or from a piece of interaction within the group. A citation could be made up of a phrase, a part of a phrase or several consecutive phrases. The video recordings, audio recordings and moderators' notes were also evaluated for the purpose of understanding the overall context of the data and for appreciating the nuances. The second data display was manually re-arranged into the third, the third into the fourth and so on. Open coding was used to sort and to re-sort the data. The sequence of the data displays aligns with the incremental condensation of the data to the point that conclusions could be drawn.

Massey's [45] distinction between articulated data and attributional data informed the means by which the analysis was conducted. Articulated data is said to be directly linked to specific questions, posed prior to the study, whereas attributional data spontaneously arises from its assignment to meaning, based on the interpretation of its relevance for issues of interest. In this study, questions 1-3 are articulated, whereas questions 4-5 are attributional, and arose only following the initial analysis of the data. Both data types can provide insights into the participants' thinking but attributional data cannot be considered to be a direct answer to a direct question. On the other hand, attributional data gains relevance and value in particular based on the attribution. The analysis and the presentation of the results were structured in a way that respects the data type and the insights that were established from the group interaction. 


\section{Findings}

Many Finnish cities are seen to have ambitious greenhouse gas (GHG) reduction targets and it appears that urban planners have an essentially unlimited mandate to devise sustainable solutions. Nevertheless, it was ascertained from the discussions that short-term economic interests have a tendency to dominate decision-making. This, in combination with the complexity of the environmental issues faced and a perceived lack of co-operation between necessary stakeholders in environmental matters, has left environmentally oriented urban planners somewhat dispirited. However, it seems that the power of urban planners is further restricted by their own beliefs. It was persistently stated in all of the groups that there are limits to what can be affected through land use planning, and participants appeared more eager to state the limitations of their power than to discuss how their work could tangibly contribute towards environmental sustainability. Surprisingly, participants did not identify a connection between urban structure and sustainable lifestyles outside of the realms of housing and daily journeys. Furthermore, it was found that urban density is considered by the participants to be an imperative characteristic of urban structures if they are to promote environmental sustainability. The findings are presented in more detail in the sub-sections below and finally summarised in Table 3 at the end of the section.

\subsection{Assessment of Environmental Sustainability in Urban Planning}

Given that the first research question- "Why is environmental sustainability assessed in urban planning?"- -was posed directly to the participants, the findings here are based on articulated data.

In some cities urban planning has rather ambitious greenhouse gas reduction targets, for example:

"Our climate strategy is very ambitious." (Group 1)

"The ambition to build carbon-neutral districts has a strong position in the city strategy." (Group 1)

"We have joined the network of carbon-neutral municipalities, and even our decision-makers are aware of the greenhouse gas reduction targets." (Group 2)

"Our aims of eco-efficiency are included in the city strategy, in the mayor's program and in the climate programs, and the target is to make more eco-efficient land-use plans." (Group 3)

However, in some others, environmental issues are still not considered to be a high priority, for example:

"There are not necessarily any greenhouse gas reduction targets, nor a climate strategy. It is easily vague the way that anything can be proved to be sustainable by suited defaults or weights." (Group 3)

"In my opinion, all issues other than environmental sustainability have been promoted more rapidly in decision-making. In some cities environmental sustainability is a political priority but in some others it depends very much on the officers on duty. We have had strategies and targets but nobody has ever been responsible for implementing them. It depends on who is involved and interested." (Group 3) 
Even if consultant companies provide a selection of environmental assessment schemes, in some cities environmental sustainability is not assessed. Instead, planning is based on common knowledge (or beliefs), for example:

"Practically, nothing is assessed. Quite a lot has been done on gut feeling, without better knowledge." (Group 2)

"Common knowledge, what we have had of land use planning. If we had knowledge based on research, we could-people talk about these things so much nowadays." (Group 2)

"We tried. One student of environmental engineering prepared an assessment tool as a part of his thesis. We tested it but it leads to irrational results." (Group 2)

"We were close to buying into one of the Finnish commercial evaluation schemes. A variety of tools exists." (Group 2)

The participants repeatedly expressed three reasons why environmental sustainability is or should be assessed in urban planning: (1) to increase the environmental knowledge of the people involved in the planning and decision-making process; (2) to prove that certain alternatives are environmentally more sustainable than others; and (3) to enable or to promote or not to prevent environmental sustainability. All the three reasons were seen both to have their own justification and to enable more specific improvements. The more detailed reasoning and the contribution of each group is presented in Table 2.

Table 2. The detailed reasons for assessing environmental sustainability in urban planning.

\begin{tabular}{|c|c|c|c|}
\hline $\begin{array}{l}\text { (1) To increase the environmental knowledge of the people involved in the } \\
\text { planning and decision-making process, in more detail: }\end{array}$ & \multicolumn{3}{|c|}{$\begin{array}{l}\text { Which focus groups identified the } \\
\text { detailed reason: }\end{array}$} \\
\hline To understand environmental consequences & Group 1 & - & Group 3 \\
\hline To label environmentally sustainable urban structures & - & Group 2 & Group 3 \\
\hline To gain broader understanding (of greenhouse gas emissions) & Group 1 & - & - \\
\hline To examine the environmental benefits of high urban density & Group 1 & - & - \\
\hline
\end{tabular}

(2) To prove that certain alternatives are environmentally more sustainable Which focus groups identified the than others, in more detail: detailed reason:

\begin{tabular}{llll} 
To justify higher urban density & Group 1 & - & Group 3 \\
To find differences & Group 1 & Group 2 & - \\
To enable benchmarking & Group 1 & Group 2 & - \\
For marketing purposes & Group 1 & Group 2 & - \\
To facilitate negotiations with stakeholders & - & Group 2 & - \\
\hline
\end{tabular}

(3) To enable or to promote or not to prevent environmental sustainability, Which focus groups identified the in more detail: detailed reason:

To enable or to promote environmental sustainability

Not to prevent environmental sustainability

$\begin{array}{lll}\text { Group 1 } & \text { Group 2 } & \text { Group 3 } \\ \text { Group 1 } & - & - \\ \text { Group 1 } & - & \text { Group 3 }\end{array}$

When the groups were asked what in particular should be assessed, the GHG emissions of traffic and housing (the energy use of buildings, in particular) strongly dominated the discussions. In addition, when asked to name sources of GHG emissions, building infrastructure was mentioned once and energy production several times. 


\subsection{The Steering Effect of Environmental Assessment to Decision-Making}

The second research question-"How does environmental assessment steer decision-making in urban planning?"-was directly posed and thus all the related results are based on articulated data.

No real disagreements were observed during the discussions about decision-making. Even if participants did not always totally agree, the tendency during the discussion was to add new viewpoints and perspectives rather than to prove someone else wrong. The interviewees did not seem to hold back and quite openly discussed the problems they experienced in their work, as if among colleagues.

The participants repeatedly expressed that short-term economic interests dominate municipal decision-making, for example:

"Climate change has been a minor factor in decision-making." (Group 1)

"It is euros that drive it. The municipal economy dominates. Unfortunately very few people think about the bigger picture, even in an economic sense." "Yes, that is the traditional way to make decisions in municipalities." (Group 2)

"It is obvious what the decision-makers think of when eco-efficiency and cost-efficiency are against each other." "What do they think of? Let us know." "Of costs. " (Group 1)

"If municipalities were involved in carbon trading, low-carbon land use plans would most probably proceed at a good pace." (Group 2)

"Win-win solutions [both environmental and monetary benefits] work well." (Group 3)

"In my opinion, the politicians spend all their time on economic considerations. They do not have time for environmental issues." (Group 3)

Furthermore, environmental issues were found complex in general and very complex to quantify, which was seen to deteriorate their position in decision-making, for example:

"Environmental issues are too complicated for an ordinary person who still has to deal with them. Contradictory information makes the challenge unbearable." (Group 1)

"The message should be simple enough that the decision-makers could understand it." (Group 2)

"It would be easier for the decision-makers to make good decisions if we could prove our arguments." (Group 3)

"For decision-making, it must be proven that something is more environmentally sustainable than something else." (Group 1)

"We do not have metrics for measuring eco-efficiency." (Group 3)

"Environmental sustainability is a relatively new aspect in decision-making, and the environmental considerations do not have a common unit, which would be as easy to understand as euros in an economic framework." (Group 1)

"Municipalities set some (greenhouse gas emission reduction) targets and then afterwards try to figure out, with the help of consultants, if they are being achieved, and if not, which actions should be taken. Currently we don't really have tools in place that could advise land use planners to mitigate the climate change." (Group 2) 
"It is still unclear when and how the improvements should be done to truly have an effect." (Group 1)

"Both urban planners and decision-makers need better knowledge." (Group 1)

“We need better knowledge to prove things—-to justify our suggestions.” (Group 2)

However, one of the groups also itemised how the dominance of short-term economic interests in decision-making can be challenged: Firstly, environmental considerations have to be presented as numbers. If strong evidence, based on reliable measurements, calculations and benchmarking, is presented as simply as possible, it has a chance to be taken into account. Strong volition, determination and activity also aid progress and increased environmental knowledge within the decision-makers was seen as being an important factor. Secondly, in order to resonate, the environmental aims should support or to be included in the city strategies and political agendas, and not conflict with them. Sometimes the environmental work should be initiated from strategy level as opposed to being initiated from actual land use planning tasks themselves. Thirdly, a widely recognised and respected environmental assessment brand that carries a strong image from a marketing perspective can facilitate environmentally oriented decision-making. The British BREEAM was mentioned as a good example, and positive experiences were seen to have a key role.

The participants stated for example:

"Decision-makers understand numbers. As long as we lean on qualitative reasoning, economic considerations dominate the environmental ones. " (Group 3)

"One must be like a horn to bring those (environmental) issues forth-to create an atmosphere that this is important." (Group 3)

"If our solutions fit the definitions of policy, the chances are better that they will be accepted." (Group 3)

"It can be a self-reinforcing process. Increased understanding and obvious results make it easier and it can affect the strategy. The new strategy can then facilitate further improvements." (Group 3)

"A good example of obvious results in one city helps the progress in the others." (Group 3)

\subsection{The Role of Urban Planning and Urban Planners in Environmental Sustainability}

Only part of the third research question-What is the role of urban planning in environmental sustainability? - was revealed to the focus groups, relying on articulated data. The other half of the question-What is the role of the planners, or more specifically, how is their power to promote environmental sustainability limited? - was discussed spontaneously, as expected, encouraged by the moderators, thus providing attributional data.

According to the articulated data, in the context of current Finnish urban planning, improved environmental sustainability mainly refers to climate change mitigation. Other environmental issues were rarely mentioned in the discussions. Even if the participants often used the terms "eco-efficiency" and "environmental sustainability" they typically considered solely greenhouse gas emissions. Furthermore, it was dominantly stated in all the groups, still in an articulated sense, that only certain things can be affected through land use planning. Similarly to when the groups were asked what should 
be assessed (question 1), the GHG emissions of traffic and the heating energy use in buildings dominated the discussions about the role of land use planning in environmental sustainability. In addition, it was highlighted that land use planning can only enable, not force environmental improvements.

Based on the attributional data that emerged from the focus groups, all of the land use planners from different cities and municipalities shared an ambition to design environmentally sustainable urban environments. It is often the land use planners who conduct or subcontract the environmental assessment of urban developments. However, the participants were more eager to name what they do not have power to influence than how their work could tangibly contribute to environmental sustainability. Private driving outside of cities and in particular personal consumption and leisure related choices were seen as impossible to affect. It appears that the power of urban planners to promote environmental issues can be limited not only by formal restrictions or other people but also by their own beliefs. The participants expressed rather contradictory views and opinions about the power of land use planning.

On the one hand urban planners can suggest almost anything, for example:

"We must remember that a land use planner can ordain just anything. Land use planning truly has the means to make a difference." (Group 2)

"Basically we create the options but do not make the decision between them. The decision-makers very rarely add anything to the plans but they may well not let something through." (Group 3)

On the other hand, the lack of co-operation and joint environmental aims restrains their mandate in the environmental management of urban areas, for example:

"Land use planners do not make all the decisions. We arrange the traffic but do not choose the fuel for the combined heat and power production." (Group 1)

"We can impact urban structure but not of how private companies and municipal decision-making support our solutions. The planned bus routes may not materialise and the schools may be disbanded." (Group 2)

"Even decision-making does not always lead to operation. We wait for something to happen but everything happens so very slowly." (Group 3)

Contradictory views and opinions about the power of urban planning concerned for the most part energy production, the location of schools and kindergartens, public transportation routes and the location of supermarkets. For example:

"The route selection of bus companies cannot be affected in any way, nor can the network of schools and kindergartens. Reservations can be put into the land use plans, but different logic applies to how they are closed down." "I think it is true, but the need to travel and the means of transportation, that we do have power on. I would not be as pessimistic considering the routes of public transport either-cities and municipalities do have the possibility to get involved in developing those services." "Yes, if they want to." "And the locations of markets and schools and kindergartens are defined in particular by land use planning." "But we cannot affect the thing that they may be closed down." (Group 2) 
Rather surprisingly, the participants did not see a connection between urban structure and lifestyles or consumption choices, with the exception only of housing and daily journeys. For example:

"Could you name something important that you would like to affect through land use planning?" "People's lifestyles, but it is not an easy thing." "Yeah, people's behaviour cannot be affected in any way." (Group 2)

“We cannot affect people's lifestyles." (Group 3)

"People's leisure time is an impossible field-something we cannot affect." (Group 2)

Only once one of the participants touched upon the land use planner's power to influence personal consumption:

"Then I started to think about electric cars. Their batteries work better if the cars are not left outdoors in freezing temperatures. Should we include in land use plans orders to build heated garages underneath the apartment houses or something similar-it would be a way to affect." (Group 2)

In addition, the issue of affecting people's behaviour was once discussed as a joke:

"If travelling is bad, how about a community that we would build huge pentagons everywhere, where shopping malls, apartments and working places would be located all inside the same walls and there would be a public recreational area in the centre of the building? Blocks like that." "You are not allowed to leave." "You need a special permission to leave." "In some eastern countries there are those huge houses." "A closed ecosystem." "Effectively limits travelling." (Group 2)

\subsection{Urban Density}

Care was taken to ensure that the fourth research question- "How is urban density considered in terms of environmentally sustainable land use?"-was not articulated at all, for the purpose of allowing the issue to bubble up in unexpected contexts. Therefore, the findings here are based on solely attributional data.

It was found that density is considered to be an imperative characteristic of sustainable urban structures. Promoting higher urban density is seen to be the most straightforward means of land use planning for environmental improvements. The participants generally found increased environmental knowledge useful for examining the environmental benefits of high urban density. Their desire for environmental assessment was mainly to be able to justify higher urban density. However, the effectiveness of compacting urban populations was also questioned in two of the three focus groups.

In each group, urban density was spontaneously named as a hot topic in land use planning:

"These questions of higher urban density are surely topical in every city, in one way and another." (Group 1)

"The important thing is the land use efficiency: the difference between higher density through complementary construction and sprawl through new housing areas. Land use planning has an important stand there." (Group 2) 
"The basis for higher urban density is the same everywhere: to grow inwards, if it is the right thing to do." (Group 3)

In each group, high urban density was viewed as a key issue in the environmental sustainability of urban structure, and evidently the dominant belief was that it has a strong positive impact to environmental sustainability:

"We have a problem in that if we compress the city structure it almost always means that some green areas that are important for some people will be touched. It is inevitable. We are accused all the time of stealing green areas under the guise of climate change mitigation. To defend our proposals we should be able to measure total environmental sustainability, I think. We might for example have a low-carbon solution that is not disastrous for the local eco-system services either." (Group 1)

"Because cities grow anyway, if we plan denser urban structure the environmental benefit is the prevention of urban sprawl. We assume it to be extremely effective climate change mitigation." (Group 1)

"I believe that there are multiple reasons why complementary construction is very ecological, perhaps even more ecological than we currently think." (Group 1)

"Because we have to let people build detached houses, density is very low in new residential areas and respectively the estimate of environmental sustainability is very bad." (Group 1)

"It is important to bring the message to the decision-making process that complementary construction is far more environmentally sustainable because it might be an alternative to a new residential area. We show that because density is low in new residential areas they cannot be environmentally sustainable." "Exactly, that urban density is a key issue." (Group 1)

"The question is, how to make people willing to live densely, close to each other." (Group 2) "The more rural the municipality, the more difficult it is for the land use planners to reason higher density. We need to be able to show people that it is important environmentally." (Group 3)

"Even if higher urban density is a priority it is not being realised properly. We need to be able to show the negative environmental impact of urban sprawl." (Group 3)

"The old wooden cities are relatively dense and thus environmentally sustainable per se." (Group 3)

Nevertheless, the positive impact of high urban density to the environmental sustainability of urban structure was also questioned in two of the groups:

“[...] - if higher urban density really improves environmental sustainability.” (Group 1)

"There are contradictory results concerning whether density is ideal." (Group 1)

"At which point is urban density taken too far to the point that it deteriorates the local ecosystem services? Could it be that in some cases less radical density might be better environmentally?" (Group 3) 
"There should be a comparison of whether it's better to grow inwards or outwards in each case. In those cities where there is still land available and thus other alternatives to growing inwards, the other alternatives should be considered." (Group 3)

\subsection{Summary}

The main findings are summarised in Table 3.

Table 3. Summary of the main findings.

\begin{tabular}{|c|c|c|}
\hline Research question & Data type & Main findings \\
\hline $\begin{array}{l}\text { (1) Why is environmental } \\
\text { sustainability assessed } \\
\text { in urban planning? }\end{array}$ & Articulated & $\begin{array}{l}\text { In many Finnish cities urban planning has rather ambitious greenhouse } \\
\text { gas reduction targets. However, environmental sustainability is not } \\
\text { always assessed. } \\
\text { Environmental sustainability is, or should be, assessed for three main } \\
\text { reasons: (1) to increase the environmental knowledge of the people involved } \\
\text { in the planning and decision-making process; (2) to prove that certain } \\
\text { alternatives are environmentally more sustainable than others; and (3) to } \\
\text { enable or to promote or not to prevent environmental sustainability. }\end{array}$ \\
\hline $\begin{array}{l}\text { (2) How does } \\
\text { environmental } \\
\text { assessment steer } \\
\text { decision-making } \\
\text { in urban planning? }\end{array}$ & Articulated & $\begin{array}{l}\text { Short-term economic interests dominate municipal decision-making. } \\
\text { Environmental issues are complex in general and very complex to } \\
\text { quantify, which deteriorates their position in decision-making. } \\
\text { The domination of short-term economic interest in decision-making can also } \\
\text { be challenged. First, the environmental considerations have to be presented } \\
\text { as numbers. Second, the environmental aims should support or to be included } \\
\text { in the city strategies and political agendas, not to } \\
\text { conflict with them. }\end{array}$ \\
\hline
\end{tabular}
conflict with them

In the context of current Finnish urban planning, improved environmental sustainability mainly refers to climate change mitigation, more specifically

Articulated to the greenhouse gas (GHG) emissions of traffic and housing (the energy use of buildings, in particular).

It was highlighted that land use planning can only enable,

(3) What is the role of not force environmental improvements.

urban planning and urban planners in environmental sustainability?
The land use planners from different cities and municipalities share the ambition to design environmentally sustainable urban environments. On the one hand, urban planners can suggest almost anything. On the other hand, the lack of co-operation and joint environmental aims

Attributional restrains their mandate.

The power of urban planners to promote environmental issues can also be limited by their own beliefs. The participants did not see a connection between urban structure and lifestyles or consumption choices, apart from housing and daily journeys. 
Table 3. Cont.

\begin{tabular}{|c|c|c|}
\hline Research question & Data type & Main findings \\
\hline $\begin{array}{l}\text { (4) How is urban density considered } \\
\text { in terms of environmentally } \\
\text { sustainable land use? }\end{array}$ & Attributional & $\begin{array}{l}\text { Urban density is a hot topic in land use planning. } \\
\text { High urban density is seen to be a key issue in the environmental } \\
\text { sustainability of urban areas. } \\
\text { The dominant belief is that densification has a strong positive } \\
\text { impact on environmental sustainability. } \\
\text { Increased environmental knowledge is seen to be useful, for } \\
\text { examining the environmental benefits of high urban density and } \\
\text { for justifying higher urban density, amongst other things. }\end{array}$ \\
\hline
\end{tabular}

\section{Discussion}

A focus group study was conducted in Finland to examine how the professionals of urban planning and environmental sustainability, at both a municipal and a state level, experience the steering effect of increased environmental awareness on land use. According to Nielsen and Jensen [52], local authorities are in a unique position to steer society development and to promote sustainability. Nevertheless, the main finding of this study is that the participants see urban planning as being unable to support sustainable lifestyles in the wider meaning. The power of urban planning to impact environmental sustainability appears to be underestimated in that greenhouse gas emissions of housing and daily journeys are the dominant elements of environmental sustainability that are taken into consideration. The analysis identified three main reasons for this underestimation: (1) The relationship between land use planning and inherently immeasurable environmental sustainability appears to be too complex in the sense that urban planners cannot identify the means or to quantify the benefits of supporting more sustainable lifestyles; (2) The dominance of short-term economic issues in decision-making as well as a lack of co-operation with other planning stakeholders and the absence of joint environmental objectives demotivates land use planners; (3) The prioritisation of urban density may overrule alternative means of promoting environmental sustainability, such as the encouragement of sustainable suburban or non-urban lifestyles.

The first and the second constraints appear to strengthen one another: Due to the complexity of environmental issues, the enthusiasm to get involved is scarce and instead simple short-term economic considerations rule decision-making, especially in smaller cities where resources are very limited. The urban planners carry the burden of proving numerically that their proposals are environmentally sustainable and of creating an atmosphere in which the issue of environmental sustainability carries weight. This burden is too much for them to handle alone. The results of this study indicate that there is a communication gap between the scientific community and the local urban land use professionals. It seems that scientific knowledge about sustainability is not fully applied to support local planning and decision-making. Scientific results could potentially facilitate what the participants of the focus groups called for: to be able to prove their arguments, and to support sustainability's position in decision-making.

The third constraint - that urban density is considered to be the quintessential factor of sustainable urban planning - actually responds to the problems occurring from the first and the second constraints by (a) enormously simplifying the connection between urban planning and environmental sustainability and (b) providing potential win-win solutions with both environmental benefits and 
monetary savings for the municipality. The connection between urban planning and environmental sustainability could not be simpler or any easier to quantify than that "the higher the density, the more sustainable the development". In addition, if people are packed into dense urban areas, for example municipalities' costs for school transportation for children and taxi and ambulance services for senior citizens can be significantly reduced. Also the price of urban land may increase.

However, despite all its benefits, the belief that higher urban density is more sustainable eventually undermines the power of land use planning to impact environmental sustainability. Cities are increasingly regarded as the demand and consumption centres of the global economy and many scholars propose a consumption-based approach for the environmental analysis of urban areas [34,35,53,54]. Recent research in Finland has suggested that, due to higher overall consumption volumes, lifestyles in dense urban areas may in fact be more carbon intense than more dispersed suburban living and that rural lifestyles could possibly be less carbon intense than urban lifestyles, despite higher levels of private driving [22-24]. It was clearly stated in all of the focus groups that there are limitations to what can be impacted, in terms of environmental sustainability, through urban planning, and in particular personal consumption and leisure related choices were seen as impossible to affect. Urban planners would like to support sustainable lifestyles but it is evidently difficult in the consumption centres they create.

Even if municipalities are actively engaged in developing organizational capacity in sustainability, they have a relatively low level of financial and managerial capacity in this regard and tend to rely more on internal strategies and a top-down approach of acquiring technical expertise from professionals [55]. A case study by Book et al. [56] shows that the state remains a crucial actor in sustainability governance. The local authorities' duty is to interpret national density policies, should they exist, at the municipal and neighbourhood scales with an understanding of the local context [15]. In Finland, high urban density is included in most political agendas of urban regeneration nationwide and is the core of national land use guidelines for environmentally sustainable societies.

To some extent the findings and the inferences are supported by previous research. The focus groups found environmental issues to be complex in general and very challenging to quantify, which is seen to deteriorate their position in decision-making. According to Jordan and Lenschow [29], the state of the environment — both at the moment and in the long run — is a highly complex matter, affected by a multitude of factors. Furthermore, a multiple case study on the experiences of sustainability processes in Swedish municipalities by Keskitalo and Liljenfeldt [57] shows that the complexity of sustainability issues may make it difficult to cover the intended scope of local sustainability processes and may discourage people from working on them.

An additional finding was that the lack of co-operation between stakeholders in urban planning processes and an absence of joint environmental objectives restrain the mandate of urban planners to promote sustainability. Nielsen and Jensen [52] argue that decision makers can either promote or hinder the transition to sustainability at both a municipal and a state level. The focus group results also indicated that short-term economic interests dominate municipal decision-making. According to Theurillat and Crevoisier [58], there is a clear dissociation in time between the qualitative aspects that are crucial for environmental sustainability and the quantitative aspects of economics that are considered at the very end of the process, by which time everything has been defined from a qualitative point of view. Book et al. [56] summarise that it is difficult enough to find a solution either 
to economic competitiveness or to environmental sustainability, and finding a common solution or balance between the two is even more daunting.

According to Bulkeley and Betsill [3], tackling environmental problems at a municipal level is important for multiple reasons. One is that cities are sites of concentrated high consumption and waste production. Another is that local authorities are both willing and able to take on board the complex agenda of sustainable development. The main concern rising from the results of this study is indeed, if the land use planners do not see a connection between urban structure and lifestyles related consumption patterns, how are they able to limit the urban trend of high consumption and production of waste?

The study includes multiple uncertainties concerning all the three phases of the research process: data collection, data analysis, and the inference leading to conclusions. Firstly, focus groups were used as the only source of data collection, and only three homogenous groups were arranged. The choice was based on Massey's [45] idea that, "while surveys typically address the degree to which certain standards have been met across the community, focus groups may provide clues as to what the standards are". This study does not claim to have statistical validity, but rather to have provoked important interactive discussion and reported the findings respectively.

An additional consideration is that focus-group based research is never a direct and straightforward process of generating data, conducting the analysis and interpreting the results. Instead, the manner in which focus groups are used defines what can be known and how things are known [41]. Data collection and analysis was a careful and thorough process, which especially attempted to distinguish the attributional data (and the research themes that were only partially revealed) from articulated data (and firmly grounded research themes), as Massey [45] suggests.

Thirdly, the focus group method gives emphasis to the power of articulation and may thus favour the participants who perform well in articulating their opinions while those less articulate will less readily share or communicate their opinions [59]. Even if the moderators were advised to encourage the more introverted members of the groups, not everyone had equal input into the research data. However, this issue was well understood and any finding that was reported was required to be supported by both the textual data sets and by the general understanding the researchers had gained from their participation in the focus group meetings and from secondary viewings of the video recordings. Although in the results section brief, disconnected citations are used to illustrate the most interesting content of the group discussions, during analysis phase the whole data set was interpreted in the wider context of the discussion.

It would have been interesting to analyse the focus group data with respect to the varying backgrounds of the participants and thus to examine the differences in conception among different professionals. However, the data set appeared not to be adequate for such analysis. Given that both articulated and attributional data were collected, the group discussions were purposefully rather unstructured and different professionals did not necessarily express their views even-handedly. Furthermore, the samples of different professions were so small that other more personal qualities and characteristics, as opposed to factors relating to professional background, might have been the dominant influencing factor in their conceptions. Therefore, although the participants of the study appeared to adequately represent the professionals of urban planning and environmental sustainability as a whole, the number of participants of each specific profession was insufficient to represent a valid sample. 
Fourth, the interpreted results from the focus group meetings were not verified with the participants. According to Morse et al. [60], several methodologists have warned against member checks, seeing them more as a threat to validity. Given that the results are typically synthesized, decontextualized and abstracted, individual participants are actually unlikely able to recognise their particular experiences and thus unable to judge the analysis to be correct or not. In the worst case, member checks may force the researcher to keep the level of analysis inappropriately close to the data [60]. Finally, the inference leading to conclusions cannot be justified by anything else than the logic of thinking that is based on proper understanding of the larger context of the themes and on familiarisation of the relevant literature, which is described in detail above to allow critical review.

\section{Conclusions}

This study suggests that land use planners are not by themselves able to deploy the full potential power of urban planning to impact environmental sustainability. Attempts to reduce private driving and the heating energy use in buildings through higher urban density may lead to situations where the alternative patterns of land use are ruled out - patterns that could potentially support sustainable lifestyles and reduce the overall environmental burden of all consumption. Purposeful co-operation, ambitious and jointly-held environmental objectives, critique on prioritising short-term economic considerations over long-term environmental concerns and better quantification of environmental sustainability through consumption-based approach to the environmental evaluation of land use are all needed to create better futures in the form of sustainable communities.

\section{Acknowledgments}

The authors wish to thank the Finnish Funding Agency for Technology and Innovations (project 2570/31/2012) and the Academy of Finland (grant No. 268099) for financial support.

\section{Author Contributions}

Eeva-Sofia Säynäjoki is responsible for initiating, executing and writing the paper. Jukka Heinonen and Seppo Junnila provided comments and suggestions on the paper.

\section{Conflicts of Interest}

The authors declare no conflict of interest.

\section{References}

1. Myers, D.; Kitsuse, A. Constructing the future in planning: A survey of theories and tools. J. Plan. Educ. Res. 2000, 19, 221-231.

2. Grimm, N.B.; Faeth, S.H.; Golubiewski, N.E.; Redman, C.L.; Wu, J.; Bai, X.; Briggs, J.M. Global Change and the Ecology of Cities. Science 2008, 319, 756-760.

3. Bulkeley, H.; Betsill, M. Rethinking Sustainable Cities: Multilevel Governance and the Urban Politics of Climate Change. Environ. Politics 2005, 14, 42-63. 
4. Shane, A.M.; Graedel, T.E. Urban environmental sustainability metrics: A provisional set. J. Environ. Plan. Manag. 2000, 43, 643-663.

5. Gunnarsson-Östling, U.; Höjer, M. Scenario Planning for Sustainability in Stockholm, Sweden: Environmental Justice Considerations. Int. J. Urban Reg. Res. 2011, 35, 1048-1067.

6. Svane, Ö.; Weingaertner, C. MAMMUT_Managing the Metabolism of Urbanization: Testing Theory through a Pilot Study of the Stockholm Underground. Sustain. Dev. 2006, 14, 312-326.

7. Kyttä, M.; Broberg, A.; Tzoulas, T.; Snabb, K. Towards contextually sensitive urban densification: Location-based softGIS knowledge revealing perceived residential environmental quality. Landsc. Urban Plan. 2013, 113, 30-46.

8. Runhaar, H.; Driessen, P.P.J. Sustainable urban development and the challenge of policy integration: An assessment of planning tools for integrating spatial and environmental planning in the Netherlands. Environ. Plan. B 2009, 36, 417-431.

9. Burton, E. Measuring urban compactness in UK towns and cities. Environ. Plan. B 2002, 29, 219-250.

10. Herold, M.; Scepan, J.; Clarke, K.C. The use of remote sensing and landscape metrics to describe structures and changes in urban land uses. Environ. Plan. A 2002, 34, 1443-1458.

11. Huang, J.; Lub, X.X.; Sellers, J.M. A global comparative analysis of urban form: Applying spatial metrics and remote sensing. Landsc. Urban Plan. 2007, 82, 184-197.

12. Schwarz, N. Urban form revisited-Selecting indicators for characterising European cities. Landsc. Urban Plan. 2010, 96, 29-47.

13. Tang, U.W.; Wang, Z.S. Influences of urban forms on traffic-induced noise and air pollution: Results from a modeling system. Environ. Model. Softw. 2007, 22, 1750-1764.

14. Zhang, M. Exploring the relationship between the built environment and non-work travel through time use modeling: A Boston case study. J. Landsc. Urban Plan. 2005, 73, 244-261.

15. Boyko, C.T.; Cooper, R. Density and Decision-Making: Findings from an Online Survey. Sustainability 2013, 5, 4502-4522.

16. Neuman, M. The Compact City Fallacy. J. Plan. Educ. Res. 2005, 25, 11-26.

17. Van Stigt, R.; Driessen, P.P.J.; Spit, T.J.M. Compact City Development and the Challenge of Environmental Policy Integration: A Multi-Level Governance Perspective. Environ. Policy Gov. 2013, 23, 221-233.

18. Ding, C.; Wang, Y.; Xie, B.; Liu, C. Understanding the Role of Built Environment in Reducing Vehicle Miles Traveled Accounting for Spatial Heterogeneity. Sustainability 2014, 6, 589-601.

19. Kenworthy, J.R. The eco-city: Ten key transport and planning dimensions for sustainable city development. Environ. Urban. 2006, 18, 67-85.

20. Van der Waals, J.F.M. The Compact City and the Environment. Tijdschr. Econ. Soc. Geogr. 2000, 91, 111-121.

21. Janssen-Jansen, L.B. Beyond sprawl: Principles for achieving more qualitative spatial development. Plan. Rev. 2005, 160, 36-41.

22. Heinonen, J.; Junnila, S. A Carbon Consumption Comparison of Rural and Urban Lifestyles. Sustainability 2011, 3, 1234-1249.

23. Heinonen, J.; Junnila, S. Implications of urban structure on carbon consumption in metropolitan areas. Environ. Res. Lett. 2011, doi:10.1088/1748-9326/6/1/014018. 
24. Heinonen, J.; Kyrö, R.; Junnila, S. Dense downtown living more carbon intense due to higher consumption: A case study of Helsinki. Environ. Res. Lett. 2011, doi:10.1088/1748-9326/ 6/3/034034.

25. Ala-Mantila, S.; Heinonen, J.; Junnila, S. Greenhouse Gas Implications of Urban Sprawl in the Helsinki Metropolitan Area. Sustainability 2013, 5, 4461-4478.

26. Heinonen, J.; Jalas, M.; Juntunen, J.K.; Ala-Mantila, S.; Junnila, S. Situated lifestyles: I. How lifestyles change along with the level of urbanization and what the greenhouse gas implications are-A study of Finland. Environ. Res. Lett. 2013, doi:10.1088/1748-9326/8/2/025003.

27. Holden, E.; Norland, I.T. Three Challenges for the Compact City as a Sustainable Urban Form: Household Consumption of Energy and Transport in Eight Residential Areas in the Greater Oslo Region. Urban Stud. 2005, 42, 2145-2166.

28. Bulkeley, H. Cities and the Governing of Climate Change. Annu. Rev. Environ. Resour. 2010, 35, 229-253.

29. Jordan, A.; Lenschow, A. Environmental Policy Integration: A State of the Art Review. Environ. Policy Gov. 2010, 20, 147-158.

30. Hall, P.; Pfeiffer, U. Urban Future 21: A Global Agenda for Twenty-first Century Cities; E.\&F.N. Spon: London, UK, 2000.

31. Whitehead, M. (Re)analysing the sustainable city: Nature, urbanisation and the regulation of socio-environmental relations in the UK. Urban Stud. 2003, 40, 1183-1206.

32. Gibbs, D.; Jonas, A. Governance and regulation in local environmental policy: The utility of a regime approach. Geoforum 2000, 31, 299-313.

33. Marvin, S.; Guy, S. Towards a new logic of transport planning. Town Plan. Rev. 1999, 70, 139-148.

34. Ramaswami, A.; Hillman, T.; Janson, B.; Reiner, M.; Thomas, G. A Demand-Centered, Hybrid Life-Cycle Methodology for City-Scale Greenhouse Gas Inventories. Environ. Sci. Technol. 2008, 42, 6455-6461.

35. Tukker, A.; Poliakov, E.; Heijungs, R.; Hawkins, T.; Neuwahl, F.; Rueda-Cantuche, J.M.; Giljum, S.; Moll, S.; Oosterhaven, J.; Bouwmeester, M. Towards a global multi-regional environmentally extended input-output database. Ecol. Econ. 2009, 68, 1928-1937.

36. Burgess, J.; Harrison, C. Environmental communication and the cultural politics of environmental citizenship. Environ. Plan. A 1998, 30, 1445-1460.

37. Bogardus, E. The group interview. J. Appl. Sociol. 1926, 10, 372-382.

38. Merton, R.; Fisk, M.; Kendall, P. The Focused Interview: A Report of the Bureau of Applied Social Research; Columbia University: New York, NY, USA, 1956.

39. Kitzinger, J. The methodology of Focus Groups: The importance of interaction between research participants. Sociol. Health Illn. 1994, 16, 104-121.

40. Morgan, D.L. Focus Groups. Annu. Rev. Sociol. 1996, 22, 129-152.

41. Skop, E. The Methodological Potential of Focus Groups in Population Geography. Popul. Space Place 2006, 12, 113-124.

42. Hemingway, S.; White, J.; Turner, J.; Dewhirst, K.; Smith, G. The Medicine with Respect Project: A stakeholder focus group evaluation. Nurse Educ. Pract. 2012, 12, 310-315.

43. Scott, A. Focussing in on focus groups: Effective participative tools or cheap fixes for land use policy? Land Use Policy 2011, 28, 684-694. 
44. Derkzen, P.; Boch, B. Partnership and role perception, three case studies on the meaning of being a representative in rural partnerships. Environ. Plan. C 2009, 27, 75-89.

45. Massey, O.T. A proposed model for the analysis and interpretation of focus groups in evaluation research. Eval. Program Plan. 2011, 34, 21-28.

46. Hollander, J.A. The social contexts of focus groups. J. Contemp. Ethnogr. 2004, 35, 602-637.

47. Morgan, D.L. Focus Groups as Qualitative Research, 2nd ed.; Qualitative Research Methods Series 16; Sage Publications: Thousand Oaks, CA, USA, 1997.

48. Guest, G.; MacQueen, K.M.; Namey, E.E. Applied Thematic Analysis; Sage Publications: Thousand Oaks, CA, USA, 2012.

49. Wiggins, G.S. The analysis of focus groups in published research articles. Can. J. Program Eval. 2004, 19, 143-164.

50. Hughes, D.; DuMont, K. Using focus groups to facilitate culturally anchored research. Am. J. Community Psychol. 1993, 21, 775-806.

51. Hyden, L.C.; Bulow, P.H. Who's talking: Drawing conclusions from focus groups-Some methodological considerations. Int. J. Soc. Res. Methodol. 2003, 6, 305-321.

52. Nielsen, S.B.; Jensen, J.O. Translating measures of sustainable development to urban districts in Copenhagen. In Proceedings of the EASST 010: Practicing Science and Technology, Performing the Social, Trento, Italy, 1-2 September 2010.

53. Turner, G.M.; Baynes, T. Soft-Coupling of National Biophysical and Economic Models for Improved Understanding of Feedbacks. Environ. Policy Gov. 2010, 20, 270-282.

54. Wiedmann, T.; Wilting, H.C.; Lenzen, M.; Lutter, S.; Palm, V. Quo Vadis MRIO? Methodological, data and institutional requirements for multi-region input-output analysis. Ecol. Econ. 2011, 70, 1937-1945.

55. Wang, B.-C.; Chou, F.-Y.; Lee, Y.-J. Ecological footprint of Taiwan: A discussion of its implications for urban and rural sustainable development. Comput. Environ. Urban Syst. 2012, 36, 342-349.

56. Book, K.; Eskilsson, L.; Khan, J. Governing the Balance between Sustainability and Competitiveness in Urban Planning: The Case of the Orestad Model. Environ. Policy Gov. 2010, 20, 382-396.

57. Keskitalo, E.C.H.; Liljenfeldt, J. Working with sustainability: Experiences of sustainability processes in Swedish municipalities. Nat. Resour. Forum 2012, 36, 16-27.

58. Theurillat, T.; Crevoisier, O. The Sustainability of a Financialized Urban Megaproject: The Case of Sihlcity in Zurich. Int. J. Urban Reg. Res. 2013, 37, 2052-2073.

59. Refsgaard, K.; Magnussen, K. Household behaviour and attitudes with respect to recycling food waste-Experiences from focus groups. J. Environ. Manag. 2009, 90, 760-771.

60. Morse, J.M.; Barrett, M.; Mayan, M.; Olson, K.; Spiers, J. Verification Strategies for Establishing Reliability and Validity in Qualitative Research. Int. J. Qual. Methods 2002, 1, 13-22.

(C) 2014 by the authors; licensee MDPI, Basel, Switzerland. This article is an open access article distributed under the terms and conditions of the Creative Commons Attribution license (http://creativecommons.org/licenses/by/4.0/). 